\title{
Comparison of Outcome of Appendectomy: Laparoscopic versus Open Surgery in Combined Military Hospital, Savar
}

\author{
Iqbal MF${ }^{1}$, Chowdhury Al ${ }^{2}$, Aziz SR ${ }^{3}$ \\ DOI:https://doi.org/10.3329/jafmc.v16i2.55299
}

\begin{abstract}
Introduction: Open appendectomy and laparoscopic appendectomy are two modalities in the treatment of appendicitis. Superiority of one over another is not clear.
\end{abstract}

Objectives: To compare per-operative and post operative outcomes between open and laparoscopic appendectomy.

Material and Methods: Prospective comparative study was conducted on patients with acute appendicitis who underwent open appendectomy $(\mathrm{OA})(\mathrm{n}=43)$ or laparoscopic appendectomy (LA) ( $n=59)$ from October 2018 to October 2019 in Combined Military Hospital (CMH), Savar. The two groups were compared in respect to patients' characteristics, duration of operation, operative findings, post operative pain, return of peristalsis, resume of oral feeding, post operative complications, return to activities and cosmesis. Statistical analysis was performed using SPSS 25.0. Continuous and categorical variables were analyzed using independent sample $t$ test and chi-square test respectively and $p<$ 0.05 was considered statistically significant.

Results: There was no statistical difference regarding patient characteristics between the two groups except total leukocyte count (TLC) and neutrophil count, both were higher in OA group $(p<0.001)$. LA group was associated with less post operative pain $(p<0.001)$, early resume of oral feed $(O A-34.74 \pm 8.34$ minutes vs LA-24.51 \pm 6.13 minutes; $p<0.01$ ), early return to light work (OA-4.26 \pm 1.3 days vs $L A-2.53 \pm 0.7$ days; $p<0.001)$, heavy work $(\mathrm{OA}-66.93+19.38$ days vs $\mathrm{LA}-37.36+10.02$ days; $p<0.001)$ and better cosmesis (highly satisfied in LA group $96.6 \%$ vs $30.2 \%$ in $O A$ group). No significant difference was seen in duration of operation $(50 \pm 13.72$ and $53.31 \pm 7.69$ minutes in OA and LA groups respectively; $p>0.05$ ). There was no significant difference in post operative complications ( $p>0.05$ ).

Conclusion: Laparoscopic appendectomy was found clearly superior to open appendectomy in terms of less post operative pain, early resume of oral feed, early return to light and heavy works and better cosmetic result. Both procedures are comparable in terms of duration of operation and post operative complications.

Key-Words: Appendicitis, Laparoscopic appendectomy, Open appendectomy.

\section{Introduction}

Acute appendicitis (AA) accounts for the commonest indication for emergency visits during daily surgical practice, and appendectomy is the most common emergent operative procedure performed worldwide ${ }^{1}$. Approximately $7 \%-10 \%$ of the general population develops acute appendicitis with the maximal incidence being in the second and third decades of life ${ }^{2,3}$. Since 1894, the first description of open appendectomy (OA) by McBurney, it was the gold standard for treating patients with acute appendicitis for more than a century4. In contrast, the first laparoscopic appendectomy (LA) was performed in 1983 by Semm, a German gynecologist 5 . In the developing countries only a few studies have been conducted comparing the two modalities in the treatment of acute appendicitis ${ }^{6}$. At present, although there is no consensus regarding the superiority of the laparoscopic approach over the conventional technique, there is trend towards greater utilization of laparoscopic appendectomy ${ }^{7,8}$.

Military personnel and their family members are highly concern about cosmetic outcome of surgery. Delay in return to strenuous activities has tremendous bearing in their career. Keeping above background in mind, we conducted a prospective study with an aim to compare the outcomes following open and laparoscopic appendectomy.

\section{Materials and Methods}

Data was collected prospectively from patients with acute appendicitis who underwent OA or LA from October 2018 to October 2019 in the surgery department of CMH Savar. The study was approved by the research and ethics committee of $\mathrm{CMH}$, Savar. The clinical data sheet contained information such as patients' characteristics, duration of operation, operative findings, postoperative pain, return of peristalsis, resume of oral feeding, return to light and heavy activities, post operative complications and cosmesis. The diagnosis of appendicitis was made based on the presence of right lower quadrant pain, nausea or vomiting, and tenderness in right iliac fossa on physical examination. Abdominal ultrasound was performed routinely. Exclusion criteria included pregnancy, homodynamic instability, psychiatric illness and appendectomy done in conjunction with other surgeries. The decision about the type of the operation was made according to the patient's preference and experience of the surgical team.

1. Lt Col Mohammad Faruq Iqbal, MBBS, FCPS, Classified Specialist in Surgery, CMH, Savar, (Email: faruqiqbal79@gmail.com) 2. Maj Arif Imtiyaz Chowdhury, MBBS, DA, Graded, Specialist in Anesthesiology, CMH Savar 3. Maj Sharkar Rushdi Aziz, MBBS, Medical Officer, CMH, Savar. 
Prior to the surgery, all the patients received a standard regimen of intravenous antibiotics (1.0 gm of ceftriaxone / $200 \mathrm{mg}$ of ciprofloxacin). Provided purulent appendicitis was not observed at surgery, two additional doses were given. In patients with complicated appendicitis, antibiotics were not discontinued but were modified according to the culture results. OA was typically performed through a $3 \mathrm{~cm}$ Lanz muscle splitting incision in the right lower quadrant. Mesoappendix was tied and appendix was transfixed with absorbable suture. Appendix was removed and wound was closed in layers. In the presence of complicated appendicitis the abdomen was irrigated with warm saline solution and drain was kept in selective cases.

In the LA, $10 \mathrm{~mm}$ primary port was made just above the umbilicus by open or close technique and pneumoperitoneum was produced by continuous pressure of $10-12 \mathrm{mmHg}$ of carbon dioxide. Following gas insufflations, a 0 degree laparoscope was placed via primary port and two additional trocars, a $10 \mathrm{~mm}$ second trocar in the left lower abdominal quadrant and a $5 \mathrm{~mm}$ third trocar in the right lower abdominal quadrant were introduced under direct visualization. The patient was placed in a Trendelenburg position, with a slight rotation to the left. The abdominal cavity was thoroughly inspected in order to exclude other intra-abdominal or pelvic pathology. After dissecting the mesoappendix, a titanium clip was put at the base and cautery was used. Appendix was secured with a hemo lock clip, two another titanium clips were applied and appendix was divided between two titanium clips. The specimen was delivered through left lower quadrant trocar. All specimens were sent for histopathology.

The patients were not given oral feed until they were fully recovered from anesthesia and had their bowel sounds returned and then clear fluids were started. Soft diet followed by regular diet was introduced when the patients tolerated the liquid diet and had passed flatus. Patients were discharged once they were able to take regular diet, afebrile, and had good pain control. A standardized questionnaire was used to record the data. All the operative details were recorded. The operative time (minutes) for both the procedures was counted from the skin incision to the last skin stitch applied. Pain was measured qualitatively (subjectively) using visual analog scale. Postoperative complications were recorded in the proforma during the hospital stay and up to three month (two weekly visits in OPD). Wound infection was defined as redness or purulent or seropurulent discharge from the incision site observed within 30 days postoperatively.

Statistical analysis was performed using SPSS statistical software, version 25.0 (SPSS Inc., Chicagi, IL). The data were expressed as mean with standard deviation, mode, range and percentage as applicable. Independent patient characteristics (gender, ASA score) were analyzed by Chi-square test whereas dependent characteristics were analyzed by independent sample t test. In the same way per operative and postoperative continuous and categorical variables were analyzed using independent sample tests and chi-square test respectively and $p$ value of less than 0.05 was considered statistically significant.

\section{Results}

Among 102 patients 63(61.7\%) were male and 39(38.3\%) were female with male-female ratio of 1.62:1. Out of 102 patients 43 were in OA group and 59 patients in LA group. Mean age of

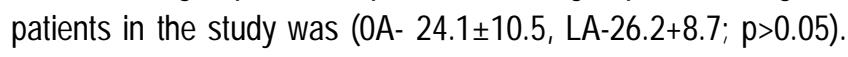
Mean TLC count with standard deviation in OA and LA group were12.6 \pm 3.6 and $9.9 \pm 2.6$ respectively $(p<0.001)$. Mean neutrophil count in percent was (OA-75.8 $\pm 9.9, \mathrm{LA}-66.5 \pm 11.2)(p<0.001)$. Most of the patients (66.7\%) were of American Society of Anesthesiologists (ASA) 1, followed by ASA 2 (31.4\%) and ASA 3 (2\%). Difference between two groups was not statistically significant ( $p>0.05)($ Table-l).

Macroscopic appearance of appendix in two groups were significantly different $(p<0.05)$. Inflamed appendix was most common findings (OA-30.4\%, LA-52.0\%) followed by perforated appendix with localized abscess (OA-4.9\%, LA-2.9\%). Difference of duration of operation in two groups was not significant $(p>0.05)$. Mean duration of operation were $50 \pm 13.7$ and $53.3 \pm 7.7$ minutes in $O A$ and LA groups respectively ( $p>0.05$ ). There was no event of open conversion of laparoscopic cases. All the laparoscopic cases and most of the open cases (67.4\%) were performed by consultants $(p<0.001)$ (Table-II).

Post operative pain in first 24 hours was compared by numeric rating score. Pain score was significantly higher in $\mathrm{OA}$ group ( $p<0.001$ ). In OA group, $83.7 \%$ patients had pain score $7 / 6$ whereas $91.5 \%$ of patients had pain score $3 / 4$ in LA group. Peristalsis returned significantly earlier in LA group $(p<0.001)$. Mean time for return of peristalsis in $\mathrm{OA}$ and $\mathrm{LA}$ groups were $24.1 \pm 6.5$ and $16.2 \pm 5.8$ minutes respectively. Resume of oral feeding following operation was also significantly faster in LA group $(p<0.01)$. Mean time for resume of oral feeding in OA and LA groups were 34.7 \pm 8.3 and $24.5 \pm 6.1$ minutes respectively. Patients were quite faster in retuning light and heavy works in LA group $(p<0.001)$. No patient in LA group and 02 patients in $\mathrm{OA}$ group develop surgical site infection, whereas one patient in each groups develop sub acute intestinal obstruction. However these findings were not statistically significant ( $p>0.05)$ (Table-III).

Histological pattern of appendix was analyzed in this series. Acute appendicitis was the most common variety (34.3\%) followed by recurrent appendicitis (33.3\%), normal appendix (17.6\%) and complicated appendicitis (14.7\%). Normal appendix was found more in female $(28.2 \%)$ than male $(11.1 \%)(p<0.01)$. Complicated appendicitis was also more common in male (22.2\%) than female (2.6\%). In LA group, 96.6\% patients were highly satisfied with the cosmetic results whereas only $16.3 \%$ patients were highly satisfied in OA group. About $30.2 \%$ patients were not at all satisfied with cosmetic results in OA group but no 
patient was unsatisfied in LA group $(p<0.001)$ (Table-IV). No mortality was observed in either group.

Table-l: Patient Demographics ( $\mathrm{n}=102)$

\begin{tabular}{|l|c|c|c|}
\hline Characteristics & OA $(\mathbf{n}=43)$ & LA $(\mathbf{n}=59)$ & p value \\
\hline Age (mean \pm SD) & $24.1 \pm 10.5$ & $26.2 \pm 8.7$ & $>0.05$ \\
\hline Gender (male / female) & $27 / 36$ & $16 / 23$ & $>0.05$ \\
\hline TLC (mean + SD) & $12.6 \pm 3.6$ & $9.9 \pm 2.6$ & $<0.001$ \\
\hline Neutrophil percent (mean + SD) & $75.8 \pm 9.9$ & $66.5 \pm 11.2$ & $<0.001$ \\
\hline ASA score (1/2/3) & $26 / 16 / 01$ & $42 / 16 / 01$ & $>0.05$ \\
\hline
\end{tabular}

Note: TLC-Total leucocyte count, SD- standard deviation

Table-II: Operative variables $(n=102)$

\begin{tabular}{|c|c|c|c|c|}
\hline \multicolumn{2}{|c|}{ Variables } & $O A(n=43)$ & LA (n=59) & $p$ value \\
\hline \multirow{5}{*}{$\begin{array}{l}\text { Macroscopic } \\
\text { appearance of } \\
\text { appendix }\end{array}$} & Normal & $01(0.9 \%)$ & $03(3.0 \%)$ & \multirow{5}{*}{$<0.05$} \\
\hline & Inflamed & $31(30.4 \%)$ & $53(52.0 \%)$ & \\
\hline & Gangrenous & $01(0.9 \%)$ & 00 & \\
\hline & Perforated & $05(4.9 \%)$ & 00 & \\
\hline & $\begin{array}{l}\text { Perforated with } \\
\text { localized abscess }\end{array}$ & $05(4.9 \%)$ & $03(3.0 \%)$ & \\
\hline \multicolumn{2}{|c|}{ Duration of operation (minutes) } & $50 \pm 13.7$ & $53.3 \pm 7.7$ & $>0.025$ \\
\hline \multirow{2}{*}{$\begin{array}{l}\text { Operating } \\
\text { surgeon }\end{array}$} & Consultant & $29(67.4 \%)$ & $59(100 \%)$ & \\
\hline & Resident & $14(32.6 \%)$ & 00 & \\
\hline
\end{tabular}

Table-III: Post operative outcome variables ( $\mathrm{n}=102)$

\begin{tabular}{|l|c|c|c|}
\hline \multicolumn{1}{|c|}{ Variables } & OA (n=43) & LA (n=59) & p value \\
\hline $\begin{array}{l}\text { Numeric rating score } \\
\text { (NRS) }\end{array}$ & $\begin{array}{c}\text { Range (5-8) } \\
\text { Mode (7,6) (83.7\%) }\end{array}$ & $\begin{array}{c}\text { Range (2-7) } \\
\text { Mode (3.4) (91.5\%) }\end{array}$ & $<0.001$ \\
\hline Return of peristalsis & $24.1 \pm 6.5$ & $16.2 \pm 5.8$ & $<0.001$ \\
\hline Resume of oral feed & $34.7 \pm 8.3$ & $24.5 \pm 6.1$ & $<0.01$ \\
\hline Return to light work & $4.3 \pm 1.3$ & $2.5 \pm .70$ & $<0.001$ \\
\hline Return to heavy work & $66.9 \pm 19.4$ & $37.4 \pm 10.0$ & $<0.001$ \\
\hline $\begin{array}{l}\text { Surgical site infection } \\
\text { (Y/N) }\end{array}$ & $2 / 41$ & $0 / 59$ & $>0.05$ \\
\hline Cosmesis (H/R/N) & $7 / 23 / 13$ & $57 / 2 / 0$ & $<0.001$ \\
\hline
\end{tabular}

Note: $\mathrm{H}$ - highly satisfied, $\mathrm{R}$ - reasonably satisfied, $\mathrm{N}$ - not satisfied

Table-IV: Histopathological pattern of appendix ( $n=102)$

\begin{tabular}{|l|c|c|c|c|}
\hline Histopathology & $\begin{array}{c}\text { OA } \\
\mathbf{n}(\%)\end{array}$ & $\begin{array}{c}\text { LA } \\
\mathbf{n}(\%)\end{array}$ & $\begin{array}{c}\text { Total } \\
\mathbf{n}(\%)\end{array}$ & p value \\
\hline Normal appendix & $05(11.6)$ & $13(22.0)$ & $18(17.7)$ & \\
\hline Recurrent appendicitis & $08(18.6)$ & $26(44.1)$ & $34(33.3)$ & \\
\cline { 1 - 4 } Acute appendicitis & $20(46.5)$ & $15(25.4)$ & $35(34.3)$ & \multirow{2}{*}{$<0.01$} \\
\hline Complicated appendicitis & $10(23.3)$ & $05(8.5)$ & $15(14.7)$ & \\
\cline { 1 - 3 } Total & $43(42.2)$ & $59(57.8)$ & $102(100)$ & \\
\hline
\end{tabular}

\section{Discussion}

Although more than 35 years have elapsed since the introduction of laparoscopic appendectomy, there is no consensus on its advantages and disadvantages compared to the conventional technique. Majority of patients attending surgical emergency room due to appendicitis are young, active professionally and socially. Moreover they are highly concern about their career. Uneventful surgery, uncomplicated, painless and quicker post operative recovery, shorter foodless period, faster return to normal activities and better cosmetic results are the expectations of present era. Bearing in mind, the present day patient demand and doubtful superiority of laparoscopic appendectomy over open conventional surgery, we conducted our study to assess the difference and acceptance of the procedures. In this study, patient characteristics in terms of age, sex and ASA score, between two groups were similar. Same demographics were seen in several studies ${ }^{9-11}$.

Generally, it is accepted that laparoscopic procedures may take longer times especially during early learning periods, when performed by inexperienced surgeons ${ }^{9}$. However, shorter operative time during LA was also reported, which might be explained by degree of experience and better visualization during laparoscopy ${ }^{10}$. In our study, mean duration of operation in two groups was comparable and difference was not statistically significant $(p>0.05)$. This finding was supported by few studies ${ }^{11-13}$ and not supported by other studies ${ }^{14-17}$. In this study, 4.7\% patient in OA group and 00\% in LA group develop surgical site infection which was not statistically significant $(p>0.05)$. Similar observations were reported from other studies $^{2,11,15,18}$. Significantly higher infection rate was seen in $O A$ group in few studies ${ }^{7-10,13,19}$. Some studies have reported statistically significant postoperative ileus in LA group compared to $O A^{2,19}$. But only one patient in each group developed paralytic ileus in our study, which was not statistically significant. As far as post operative pain is concern, our study revealed significantly less pain in LA group $(p<0.001)$. Some studies have reported less pain after laparoscopic appendectomy $y^{7,16,20}$ and other studies found no difference in pain ${ }^{12,18}$.

Early return of peristalsis and early resumption of oral feeding in LA group were two important beneficiary findings in our study. Both the findings were statically significant $(p<0.001$ and $p<0.01)$. Less tissue handling and less post operative pain are the probable reasons of such findings. Similar finding was seen in few studies ${ }^{2,9,19,21}$ and opposing finding in another study ${ }^{15}$. Early return to light and heavy works was observed in LA group in our study $(p<0.001)$ which was supported by few studies ${ }^{17,20,21}$. When question comes about patient satisfaction regarding cosmetic result, LA was far more superior to $O A(p<0.001)$. No mortality was observed in either group in our study. Similar finding was seen in another study ${ }^{18}$.

\section{Conclusion}

Both open and laparoscopic appendectomy is equally safe procedure in terms of per-operative and post operative complications in either sex. However laparoscopic appendectomy has the added advantage of less post operative pain, early resume of oral feed, early return to light and heavy works and better cosmetic result.

\section{References}

1. Ingraham AM, Cohen ME, Bilimoria KY et al. Comparison of outcomes after laparoscopic versus open appendectomy for acute appendicitis at 222 ACS NSQIP hospitals. Surgery 2010; 148(4):625-35; discussion 635-7. 
2. Kumar B, Samad A, Khanzada TA et al. Superiority of laparoscopic appendectomy over open appendectomy: The Hyderabad experience. Rawal Med J. 2008; 33:165-8.

3. Fahim F, Shirjeel S. A comparison between presentation time and delay in surgery in simple and advanced appendicitis. J Ayub Med Coll Abbottabad 2005; 17:37-9.

4. McBurney $\mathrm{C}$. The incision made in the abdominal wall in case of appendicitis with a description of a new method of operating. Ann Surg. 1894; 20:38-43.

5. Semm K. Endoscopic appendectomy. Endoscopy. 1983; 15:59-64.

6. Sheikh AR, Sangrasi AK, Shaikh GA. Clinical outcomes of laparoscopic versus open appendectomy. JSLS. 2009; 13:574-80.

7. Sauerland S, Lefering R, Neugebauer EA. Laparoscopic versus open surgery for suspected appendicitis. Cochrane Database Syst Rev 2004; CD001546

8. Merhoff AM, Merhoff GC, Franklin ME. Laparoscopic versus open appendectomy. Am J Surg. 2000; 179: 375-8.

9. Wei B, Qi CL, Chen TF, et al. Laparoscopic versus open appendectomy for acute appendicitis: a metaanalysis. Surg Endosc. 2011; 25(4):1199-208.

10. Yau KK, Siu WT, Tang CN, Yang GP, Li MK. Laparoscopic versus open appendectomy for complicated appendicitis. J Am Coll Surg. 2007; 205(1):60-5.

11. Peiser HG, Greenberg D. Laparoscopic versus open appendectomy: results of a retrospective comparison in an Israeli hospital. Isr Med Assoc J. 2002; 4:91-4.

12. Kehagias I, Karamanakos SN, Panagiotopoulos S, et al. Laparo- scopic versus open appendectomy: Which way to go? World J Gastroenterol. 2008; 14(31):4909-14.

13. Biondi A, Stefano CD, Ferrara $F$ et al. Laparoscopic versus open appendectomy: A retrospective cohort study assessing outcomes and cost-effectiveness. World Journal of Emergency Surgery. 2016; 11(1):44.

14. Ali R, Khan MR, Pishori TM et al. Laparoscopic appendectomy for acute appendicitis: Is this a feasible option for developing countries? Saudi J Gastroentero.I 2010; 16:25-9.

15. Katkhouda N, Mason RJ, Towfigh S et al. Laparoscopic Versus Open Appendectomy:A Prospective Randomized Double-Blind Study. Ann Surg. 2005; 242:439 -50.

16. Khalil J, Muqim R, Rafique M et al. Laparoscopic versus open appendectomy: A comparison of primary outcome measures. Saudi J Gastroenterol. 2011; 17:236-40.

17. Islam SR, Pasha K, Rahman S et al. Laparoscopic vs Open Appendectomy: A Comparative Study, Bangladesh Journal of Endosurgery. 2014; 2(1):5-8.

18. Katkhouda N, Mason RJ, Towfigh S et al. Laparoscopic versus open appendectomy: A prospective randomized double-blind study. Ann Surg. 2005; 242:439-48.

19. Aziz $O$, Athanasiou T, Tekkis PP et al. Laparoscopic versus open appendectomy in children: a meta-analysis. Ann Surg. 2006; 243:17-27.

20. Hellberg A, Rudberg C, Kullmann E et al. Prospective randomized multicentre study of laparoscopic versus open appendectomy. Br J Surg. 1999; 86:48-53.

21. De UTPAL. Laparoscopic versus open appendectomy in West Bengal, India. Chinese Journal of Digestive Diseases. 2005; 6:165-9. 